\title{
Valgus Knee Angle during Drop Landing in Female and Male Physical Education Major Undergraduate Students 性別與膝外翻角度及股二頭肌活動之間的關係
}

\author{
Ka-lam SAM \\ Department of Health and Physical Education, \\ The Hong Kong Institute of Education, HONG KONG \\ 答嘉林 \\ 香港教育學院健康及體育學系
}

\begin{abstract}
Gender differences in lower extremity landing mechanics and muscle activation have been identified as potential causative factors leading to the increased incidence of anterior cruciate ligament (ACL) injuries in female athletes. Valgus knee alignment places greater strain on the anterior cruciate ligament than a more neutral alignment. Biceps Femoris (BF) may provide dynamic stability to the knee joint during landing, decreasing knee valgus and preventing placing strain on the anterior cruciate ligament. The purpose of this study was to determine if frontal-plane knee angle and Biceps Femoris (BF) activation differ between the sexes at initial contact (IC) and maximal knee flexion (MKF) during a drop landing. Nine male and eight female healthy subjects volunteered to participate in this study. Frontal-plane knee angle and BF average root mean square (aRMS) amplitude were measured using BTS (Bioengineering Technology \& Systems) electromyography, video acquisition system and Kistler force platform. It was found that at initial contact, women landed in valgus, and men landed in varus $(\mathrm{P}<.001)$. At maximal knee flexion, men reached a greater varus position than women $(\mathrm{P}<.001)$. Women's $\mathrm{BF}$ aRMS amplitude was less than men. At initial contact, BF aRMS amplitude significantly differed between groups $(\mathrm{P}<.05)$. However, no significance difference between groups at maximal knee flexion $(\mathrm{P}>.05)$. To conclude, women tended to land in more knee valgus than men. At initial contact, women performed different and less BF muscle activation than men. The stabilization mechanism in landing knee motion between initial contact and maximal knee flexion is still unknown.
\end{abstract}

\section{摘 要}

股二頭肌能通過減輕滕外翻程度來增加著地時膝關節的穩定性, 從而減輕前十字愺帶受到的張力。有研究表明, 不同群體之 間下肢著地技術和肌肉活動情沉的差異是增加女子運動員前十字胡帶受傷幾率的兩大潛在因素。當膝外翻時, 十字䓵帶受到比膝 蓋處於中立位時更大的張力。本研究通過運用Kistler測力台, 肌電圖, 以及BTS視頻採集系統對 17 名(男 $=9$, 女 $=8$ )主修體育的本科 生進行測量, 目的在於討論著地瞬間膝關節的角度和股二頭肌活動是否存在性別差異, 以及測定著地緩衝後的最大膝角和股二頭 肌活動是否存在性別差異。結果發現, 在著地瞬間, 女性較男性更容易出現膝外翻現象 $(\mathrm{p}<.001) \circ$ 肌電圖顯示, 女性股二頭肌振幅 比男性要小且男女之間存在顯著性差異 $(\mathrm{p}<.05)$, 但當緩衝至最大滕角時, 男女之間的差異並不顯著 $(\mathrm{p}>.05)$ 。著地過程中, 下肢肌 肉的穩定機制與滕部運動的關係有待進一步探討。

\section{Introduction}

Anterior cruciate ligament (ACL) injury is one of the most common injuries in sports. During 2000, there were an estimated 80,000 ACL tears in the United States, with the highest risk group being participants in the 15 to 25-year-old age range in selected sports (Griffin, 2000). ACL injuries are common in sports such as basketball and team handball, which involve pivoting and cutting, as well as in Alpine skiing, where a common mechanism 
involves catching a ski tip in the snow, with the skier simultaneously twisting and falling. Approximately $70 \%$ of ACL injuries are non-contact, with most of these being sustained when the femur is rotated on the planted leg with the knee close to full extension during cutting, stopping, or landing (Boden, Dean, Feagin and Garrett, 2000; Kirkendall and Garrett, 2000). Additionally, female are 2 to 4 times more likely to sustain an ACL rupture due to a non-contact mechanism than male do in the same sports (Arendt and Dick, 1995; Arendt, Agel and Dick, 1999). In order to better understand and identify the reasons female sustain more non-contact ACL injuries than male, it is important to examine potential mechanical and neuromuscular factors affecting the knee joint complex. By uncovering differences between male and female, injury prevention programs and prescreening protocols can be developed in hopes of minimizing the number of ACL ruptures.

Current research has demonstrated that frontal plane knee motion is responsible for ACL rupture weather than sagittal plane (Kernozek, Torry, Hoof, Cowley and Tanner, 2005). Knee joint valgus is also implicated as a hazardous position for the ACL and has recently been linked to ACL injury risk (Hewett, Myer and Ford, 2005).Valgus loading can increase relative ACL strain and may reach levels high enough to cause ligamentous failure (McLean, Huang, Su and Bogert, 2004). Some researches showed that women display greater knee joint valgus than men, so valgus positioning may help to explain the sex disparity in noncontact ACL ruptures (Ford, Myer and Hewett, 2003; Ford, Myer, Toms and Hewett, 2005). Although several groups have previously examined sex differences in knee joint valgus during a double-leg drop jump (Ford, Myer and Hewett, 2003; Ford, Myer, Toms and Hewett, 2005), evidence suggests that landing on a single limb is one of the most common ACL injury mechanisms and (Olsen, Myklebust, Engebretsen and Bahr, 2004; Boden, Dean, Feagin and Garrett, 2000), thus, deserves particular attention.
The biceps femoris (BF) is the lateral hamstring and crosses the knee joint posterior to the frontal axis and lateral to the vertical axis. It joins the other hamstrings in knee flexion, but is one of the few muscles responsible for external rotation of the tibia. In this latter action, the $\mathrm{BF}$ is extremely important to the integrity of the knee joint since it is the major muscle which will neutralize the internal rotation tendencies of the other knee flexors. During a drop jump, people with a stronger BF may provide dynamic stability to the knee joint, decreasing knee valgus and preventing placing strain on the ACL.

The purpose of this study was to determine if frontal-plane knee angle and Biceps Femoris (BF) activation differ between the sexes at initial contact (IC) and maximal knee flexion (MKF) during a drop landing. We hypothesized that female will display greater knee valgus angles and less $\mathrm{BF}$ activation than male.

\section{Methods}

In this experiment, the independent variables were sex (male or female) and landing position (initial contact [IC] and maximal knee flexion [MKF]). The 2 dependent variables of interest were frontal-plane knee angles (valgus or varus) and BF average root mean square (aRMS) amplitude.

\section{Subjects}

A total of 17 healthy subjects $(9$ male and 8 female Physical Education major undergraduate students) volunteered to participate. Volunteers had not suffered any previous lower extremity injury and were not currently suffering any lower extremity injury that would prevent them from completing a single-leg drop landing.

Table1. Subject Demographics (mean \pm SD).

\begin{tabular}{lll}
\hline & Male & Female \\
\cline { 2 - 3 } & $\mathrm{N}=9$ & $\mathrm{~N}=8$ \\
\hline Height $(\mathrm{cm})$ & $174.33 \pm 4.555$ & $164.00 \pm 3.780$ \\
\hline Body Weight $(\mathrm{N})$ & $623.00 \pm 31.365$ & $530.63 \pm 26.306$ \\
\hline Age $(\mathrm{yr})$ & $22.78 \pm 1.202$ & $21.50 \pm 0.535$ \\
\hline
\end{tabular}




\section{Instrumentation}

Motion Analysis System. The movements of the lower extremity segments were tracked with a 4-camera BTS Video Acquisition System (Bioengineering Technology \& Systems) collecting at $100 \mathrm{~Hz}$. Both static and dynamic calibrations were performed, and residuals of less than $2 \mathrm{~mm}$ from each camera were deemed acceptable.
Force Platform. Subjects landed on a force platform (model Kistler 9281), which was located in the middle of the capture volume for the cameras and used to collect ground reaction force data. Ground reaction force data were collected at $500 \mathrm{~Hz}$ and were synchronized with the BTS system for simultaneous collection.

Figure 1. Spatial orientation of video acquisition system.

Bioengineering Technologies \& Systems (BTS)

Video Acquisition System

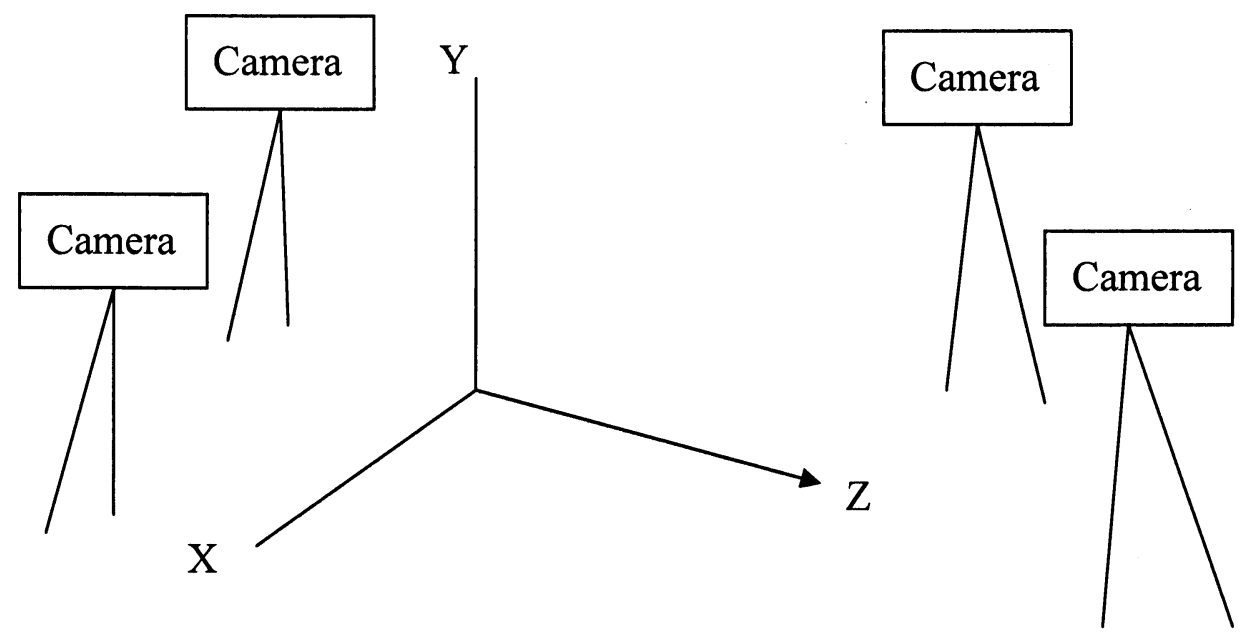

Figure 2. Spatial orientation of force platform.

Kistler Force Platform

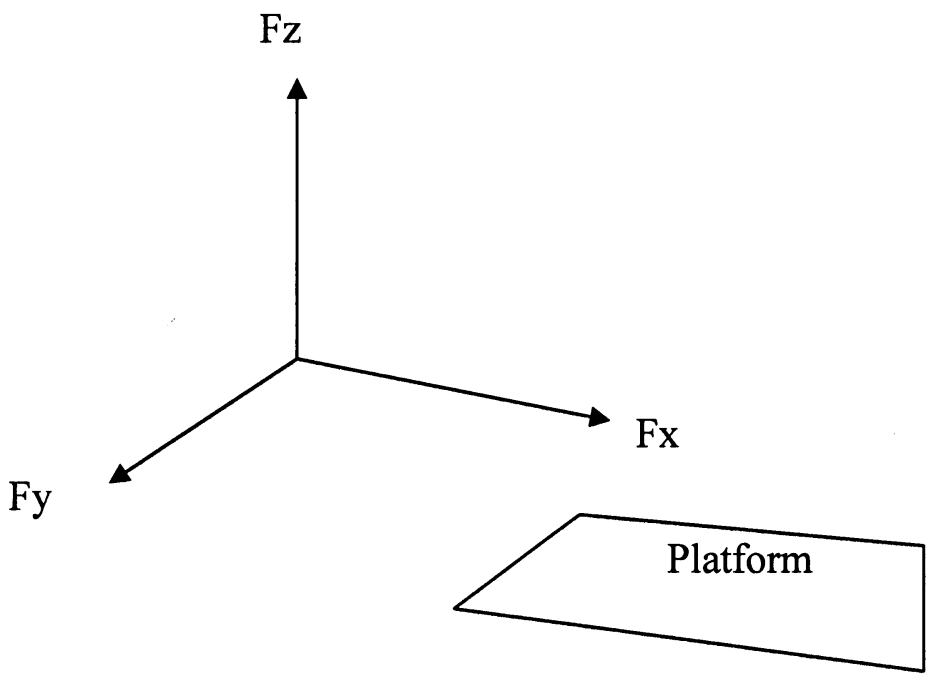

Camera 
Electromyography. Surface BF electromyography (EMG) was collected using the TeleEMG integrated with the BTS system for recording. Signals were pre-amplified with double differential EMG electrodes and collected at 100 Hz. Optical fiber was used to transmit data of signals.

Application Software. Illumination, video data collection, and analog-to-digital conversion of transducer input (force plate and BF EMG data) were synchronized and controlled by the BTS for WIN software (version 1.0), which was interfaced and controlled by a Pentium-based PC running the Windows 98 operating system (Microsoft Corp).

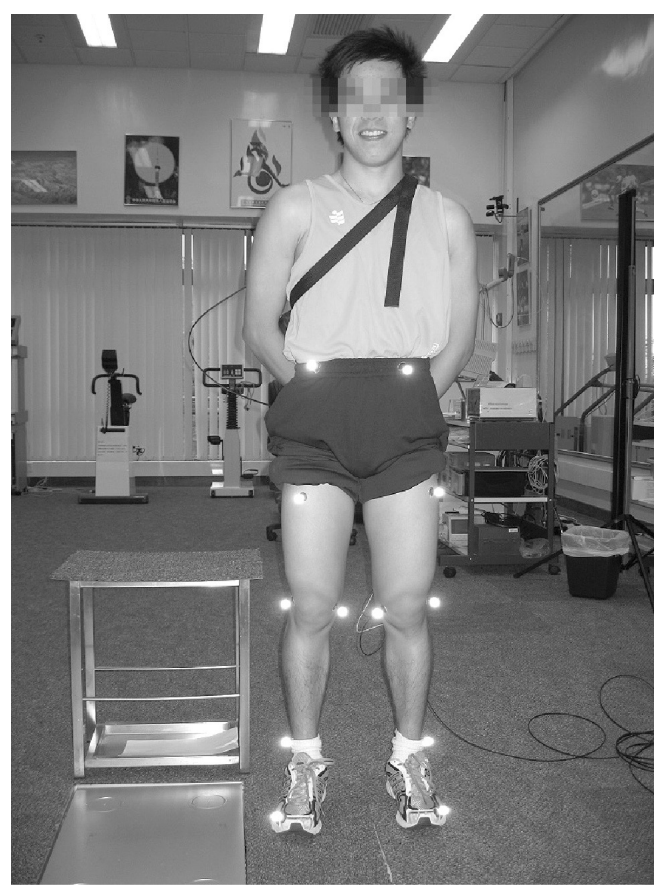

Figure 3. Experimental setting of drop jump test.

\section{Testing Procedures}

\section{Preparation}

Subjects' height, body weight and dominant leg were assessed. The operational definition of dominant leg was determined for each subject by asking which leg they would use to kick a ball with as far as possible (Ford, Myer and Hewett, 2003). 12 retroreflective surface markers were placed on the skin using double-sided tape (Figure 3). Markers were positioned on both lower limbs over the hip, upper leg, knee, ankle and toe (Figure 4). Surface EMG electrodes were placed on each subject's dominant leg over the muscle belly of the BF (Figure 5).

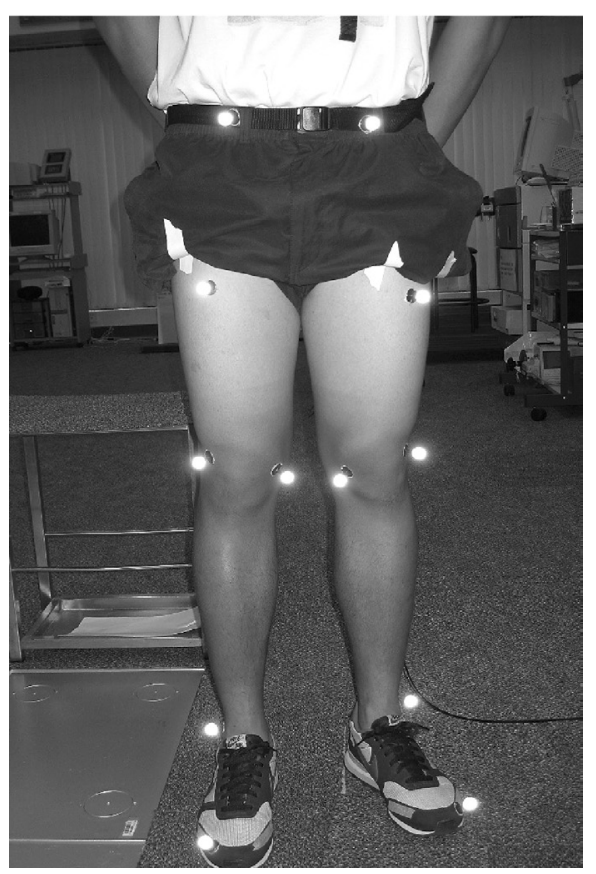

Figure 4. Placement of the 12 lower body retroreflective markers.

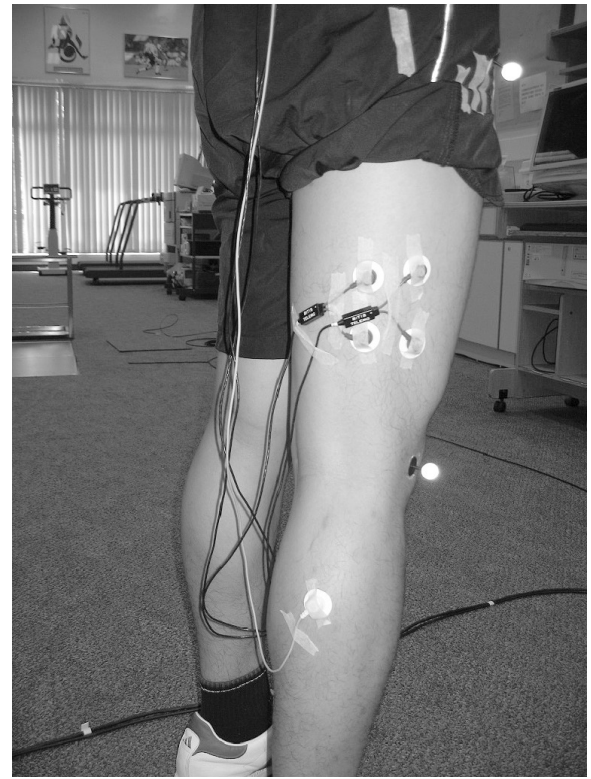

Figure 5. Placement of surface EMG electrodes (right foot). 


\section{Drop Landing Procedures}

Subjects were asked to perform a drop landing task from a $50-\mathrm{cm}$ height box. To orient participants with the landing task, each subject will be asked to perform at least 3 practice trials. Once subjects were comfortable with the task, they will be asked to perform 6 successful trials. A successful trial was defined as one in which the subject dropped down (not jump down) on the dominant leg to the force platform, "stuck" the landing for approximately 2 seconds, and did not touch the ground with the opposing limb (Russell, Palmieri, Zinder and Ingersoll, 2006). A standing single-leg static trial was taken before the drop landing trials for use in normalizing the collected EMG data. This required subjects to stand still on the dominant limb on the force platform for 5 seconds (Russell, Palmieri, Zinder and Ingersoll, 2006).

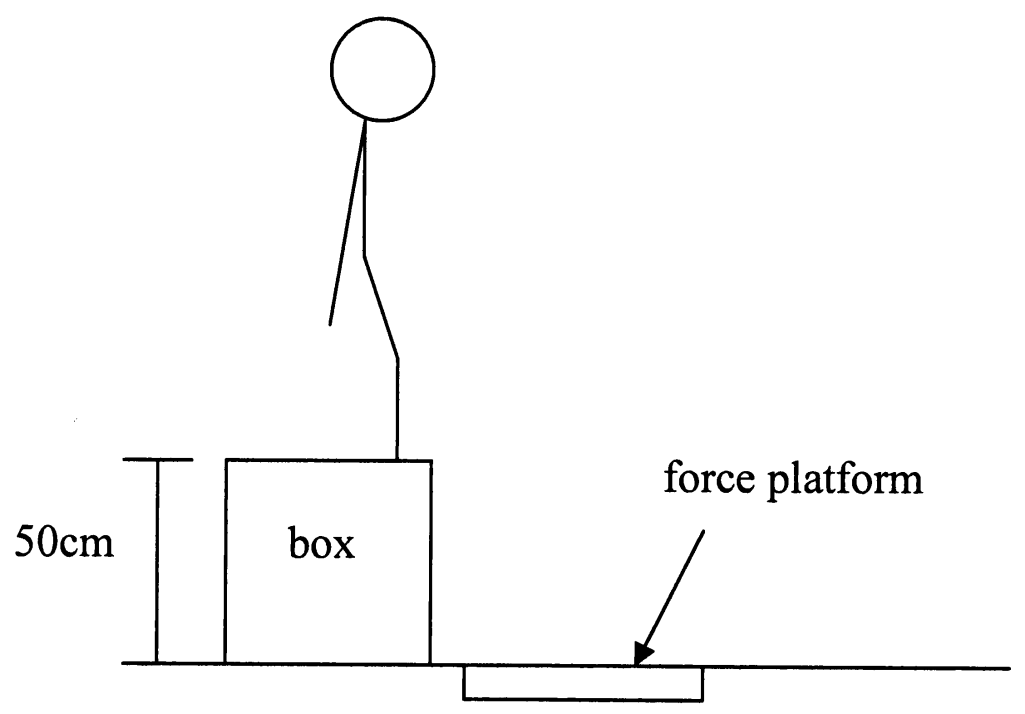

Figure 6. Setting of drop landing test.

Steps: 1. Measure body weight

2. Measure 5-second static EMG

3. Step up to the $50-\mathrm{cm}$ box

4. Perform a drop jump landing to the force platform 


\section{Data Analysis}

\section{Frontal-Plane Knee Angles}

Marker trajectory and frontal-plane knee joint angles were calculated using BTS for WIN software. Frontal-plane knee angles were identified at 2 points during the landing task: IC and MKF. Time of IC was defined as the point at which ground contact was first made with the foot, whereas MKF was defined as the peak knee flexion angle recorded upon landing on the force platform. Both IC and MKF were used only as markers to analyze frontal-plane knee-angle data. The frontal-plane knee angles for the 6 drop-landing trials were averaged and used in the statistical analyses.

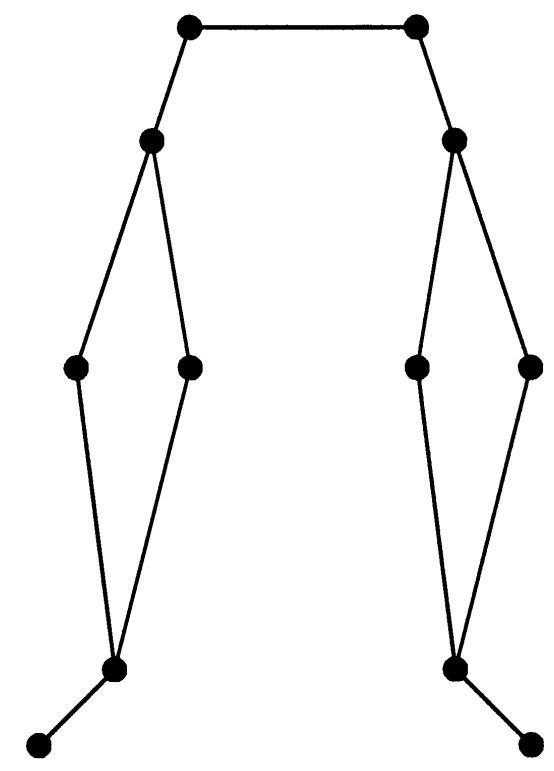

Figure 7. 12 retroreflective surface markers on lower limb.

Point of IC and MKF fontal-plane knee angle calculation

Pythagorean relationship $\mathrm{Y}^{2}+\mathrm{X}^{2}=\mathrm{R}^{2}$

Length of Upper_Leg - Ankle segment a (mm)

$=\sqrt{ }\left[\left(\mathrm{X}_{\text {upper_leg }}-\mathrm{X}_{\text {ankle }}\right)^{2}+\left(\mathrm{Y}_{\text {upper_leg }}-\mathrm{Y}_{\text {ankle }}\right)^{2}\right]$

Length of Upper_Leg - Knee segment $b(\mathrm{~mm})$

$=\sqrt{ }\left[\left(\mathrm{X}_{\text {upper_leg }}-\mathrm{X}_{\text {knee }}\right)^{2}+\left(\mathrm{Y}_{\text {upper_leg }}-\mathrm{Y}_{\text {knee }}\right)^{2}\right]$

Length of Knee - Ankle segment $c(\mathrm{~mm})$

$=\sqrt{ }\left[\left(X_{\text {knee }}-X_{\text {ankle }}\right)^{2}+\left(Y_{\text {knee }}-Y_{\text {ankle }}\right)^{2}\right]$
Cosine Rule

$a^{2}=b^{2}+c^{2}-2 * b * c * \cos \theta$

$\theta$ value

$+\mathrm{ve} \rightarrow$ varus

-ve $\rightarrow$ valgus 


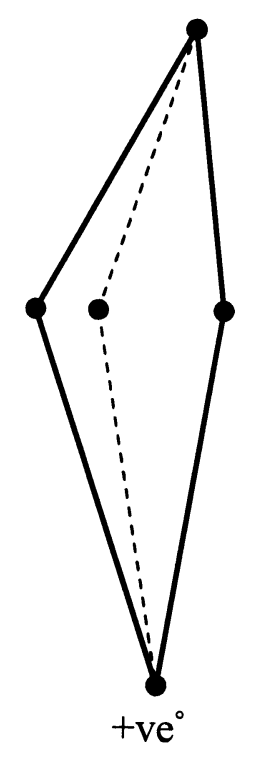

Varus

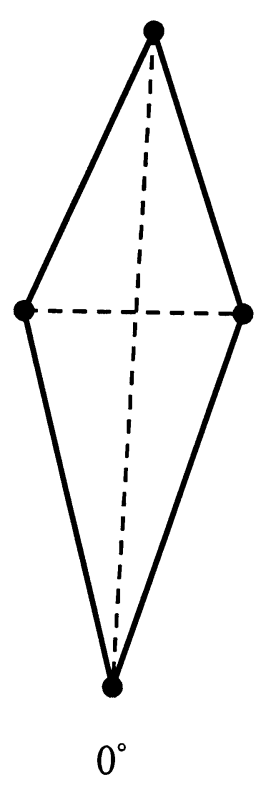

before MKF. The same time interval (100 milliseconds) was used to average $\mathrm{BF}$ root mean square EMG from the static trial. The BF aRMS amplitude data were normalized by dividing the trial averages by the BF aRMS amplitude recorded during the single-leg static trial data.

EMG normalization

EMG $(\%)=$ EMG_stactic $/$ EMG $* 100$

-ve relationship 
[01] R_BF(Short Head)

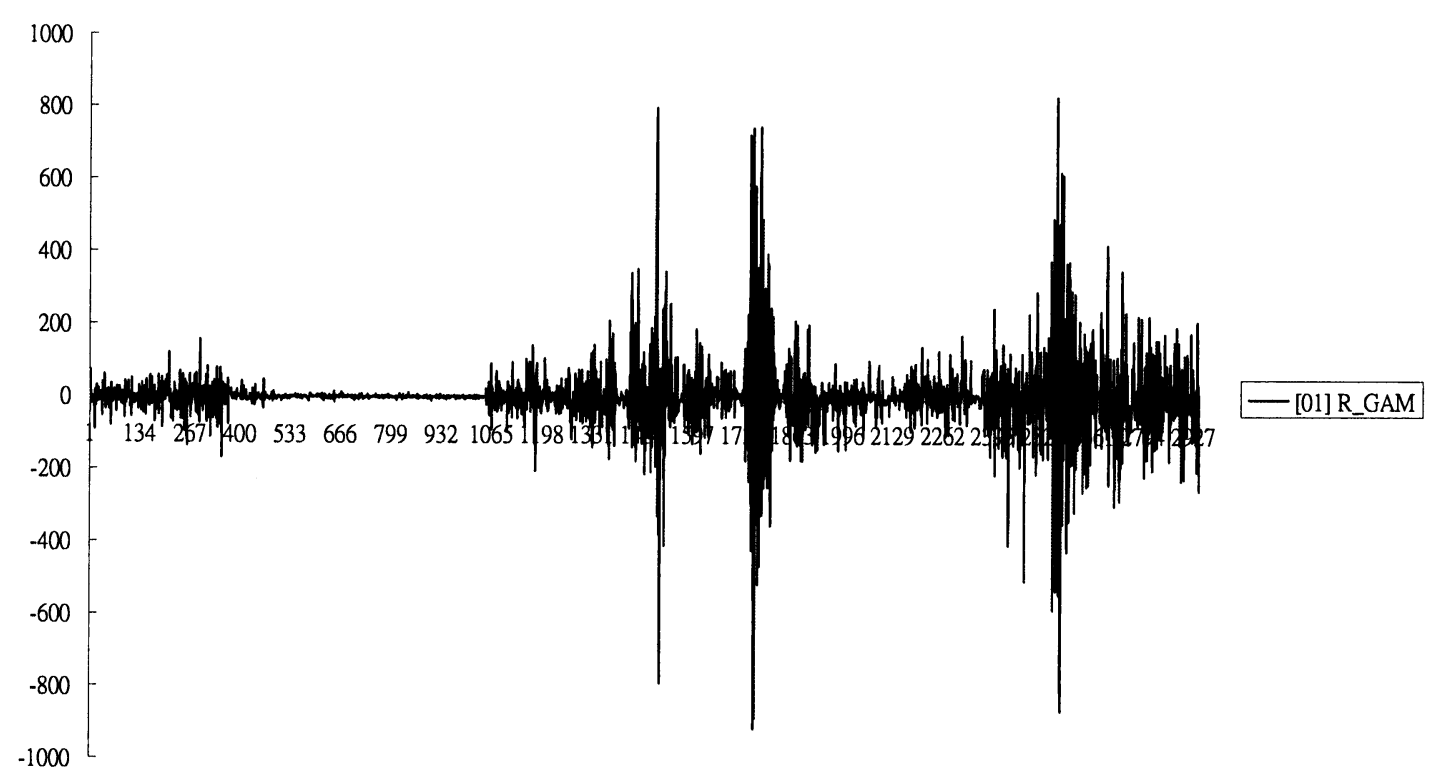

Figure 9. Electromyography of Biceps Femoris (Short Head).

[02] R_BF(Long Head)

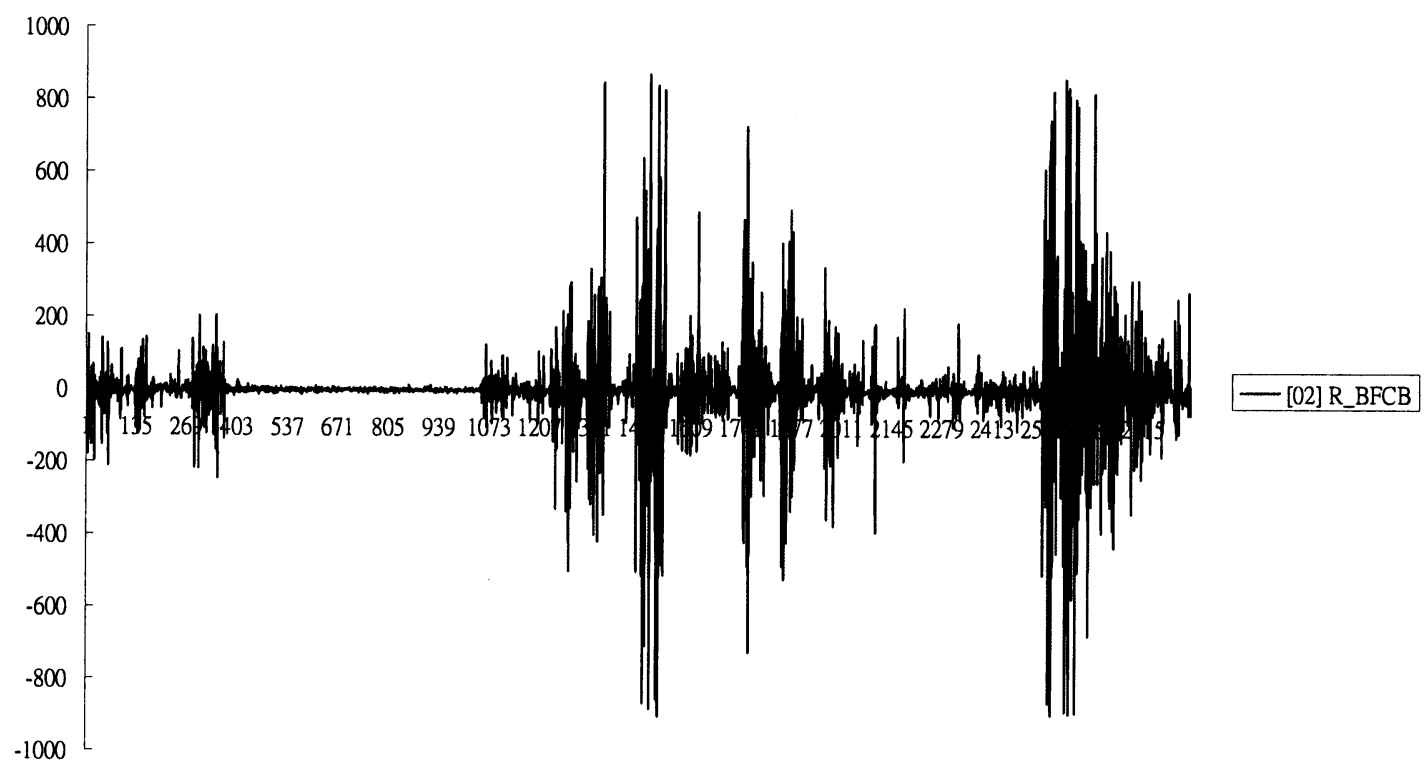

Figure 10. Electromyography of Biceps Femoris (Long Head). 


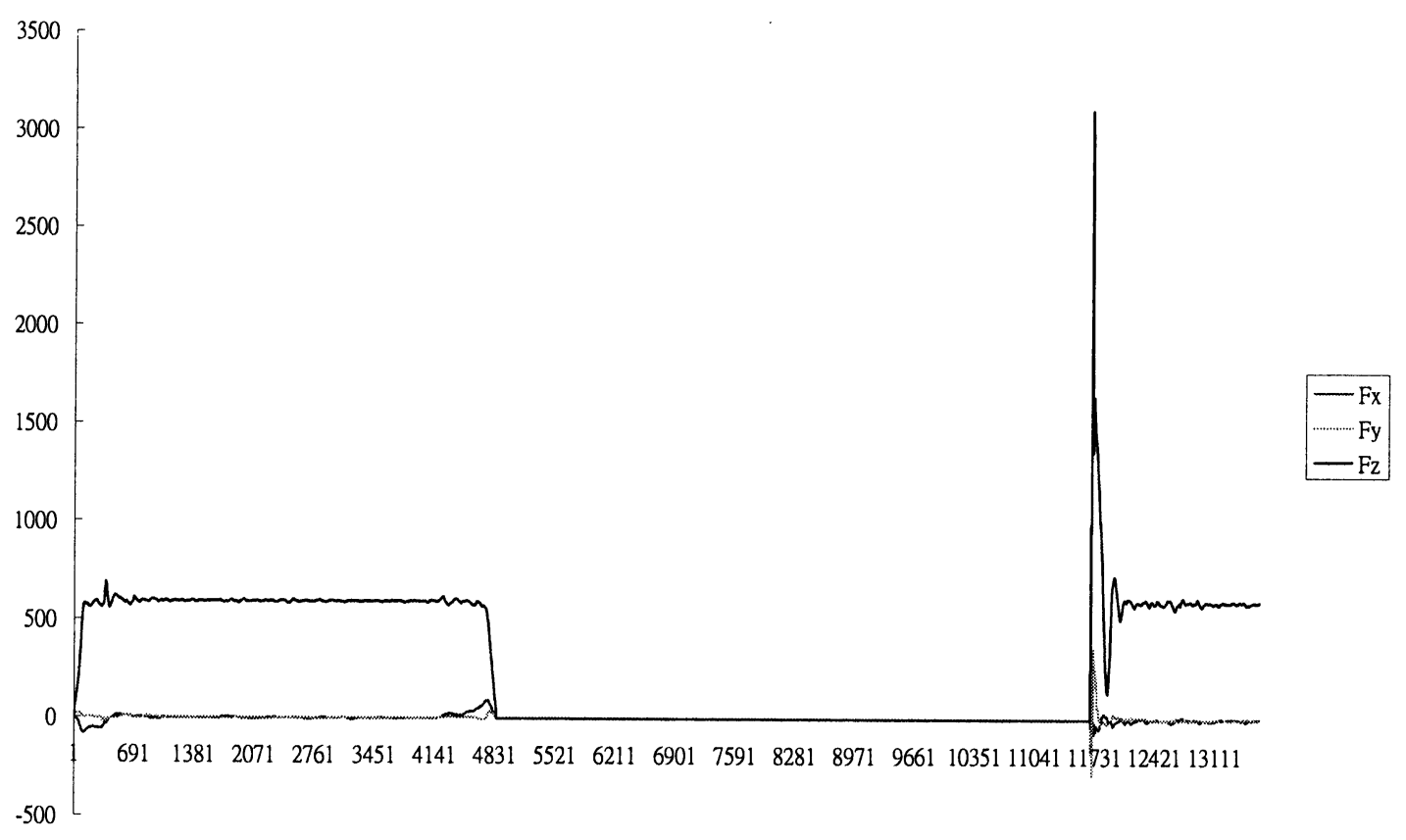

Figure 11. Force profile of drop landing task.

\section{Reliability Measurements}

2 subjects (1 male and 1 female) participated in a two-session between-day reliability assessment of the testing procedure. The tests were held on two different days and at approximately the same time of the day. All measures were evaluated by calculating the intra- class correlation coefficients from three trials of data. The measurements showed excellent reliability within session (frontal-plane knee angle at IC R=0.996, frontal-plane knee angle at MKF $\mathrm{R}=0.999, \mathrm{EMG}(\%)$ at IC $\mathrm{R}=0.987$, $\operatorname{EMG}(\%)$ at MKF $\mathrm{R}=0.992)$.

Table 2. Correlation Analysis Results.

\begin{tabular}{|c|c|c|c|c|c|}
\hline & & Knee angle IC & Knee angle $\mathrm{MKF}$ & EMG\% IC & EMG $\%$ MKF \\
\hline \multirow{2}{*}{$\begin{array}{l}\text { Knee angle at } \\
\text { IC (session 2) }\end{array}$} & Pearson Correlation & $.996(* *)$ & $.999(* *)$ & $-.995(* *)$ & $-.998(* *)$ \\
\hline & Sig. (2-tailed) & .000 & .000 & .000 & .000 \\
\hline \multirow{2}{*}{$\begin{array}{l}\text { Knee angle at } \\
\text { MKF (session 2) }\end{array}$} & Pearson Correlation & $.999(* *)$ & $.999(* *)$ & $-.987(* *)$ & $-.998(* *)$ \\
\hline & Sig. (2-tailed) & .000 & .000 & .000 & .000 \\
\hline \multirow{2}{*}{$\begin{array}{l}\text { EMG \% at IC } \\
\text { (session 2) }\end{array}$} & Pearson Correlation & $-.967(* *)$ & $-.973(* *)$ & $.987(* *)$ & $.981(* *)$ \\
\hline & Sig. (2-tailed) & .000 & .000 & .000 & .000 \\
\hline \multirow{2}{*}{$\begin{array}{l}\text { EMG \% at MKF } \\
\text { (session 2) }\end{array}$} & Pearson Correlation & $-.983(* *)$ & $-.988(* *)$ & $.994(* *)$ & $.992(* *)$ \\
\hline & Sig. (2-tailed) & .000 & .000 & .000 & .000 \\
\hline
\end{tabular}

** Correlation is significant at the 0.01 level (2-tailed)

Pearson Correlation

$$
\mathrm{R}=\sum\left(\mathrm{x}_{\mathrm{i}}-\mathrm{y}\right)\left(\mathrm{y}_{\mathrm{i}}-\mathrm{y}\right) / \sqrt{ }\left(\mathrm{x}_{\mathrm{i}}-\mathrm{y}\right)^{2}\left(\mathrm{y}_{\mathrm{i}}-\mathrm{y}\right)^{2}
$$




\section{Statistical Analysis}

A one-way analysis of variance with repeated measures on position was calculated to determine if frontal-plane knee angles differed between groups. A separate analysis of variance with repeated measures on position was computed to determine if BF aRMS amplitude differed between groups. We used SPSS (SPSS 12.0 for Windows, Release 12.0.0) to perform all statistical analyses.

Table 3. Descriptive Statistics.

\begin{tabular}{llllll}
\hline & & $\mathrm{N}$ & Mean & $\mathrm{SD}$ & $\mathrm{S}$ \\
\hline Knee angle ${ }^{\circ}$ at IC & Male & 9 & 3.4033 & .77345 & .25782 \\
\cline { 2 - 6 } & Female & 8 & -.1800 & .71812 & .25389 \\
\cline { 2 - 6 } & Total & 17 & 1.7171 & 1.98081 & .48042 \\
\hline Knee angle ${ }^{\circ}$ at MKF & Male & 9 & 15.5433 & 2.41887 & .80629 \\
\cline { 2 - 6 } & Female & 8 & 4.9100 & 3.38912 & 1.19824 \\
\cline { 2 - 6 } & Total & 17 & 10.5394 & 6.15470 & 1.49273 \\
\hline EMG \% at IC & Male & 9 & .8518 & .28025 & .09342 \\
\cline { 2 - 6 } & Female & 8 & 1.3012 & .27593 & .09756 \\
\cline { 2 - 6 } & Total & 17 & 1.0633 & .35504 & .08611 \\
\hline EMG \% at MKF & Male & 9 & 1.4976 & 1.07316 & .35772 \\
\cline { 2 - 6 } & Female & 8 & 2.3294 & .52638 & .18611 \\
\cline { 2 - 6 } & Total & 17 & 1.8890 & .93818 & .22754 \\
\hline
\end{tabular}

Table 4. Analysis of Variance (ANOVA) Results.

\begin{tabular}{|c|c|c|c|c|c|c|}
\hline & & Sum of Squares & $\mathrm{df}$ & Mean Square & $\mathrm{F}$ & Sig. \\
\hline \multirow[t]{3}{*}{ Knee angle at IC } & Between Groups & 54.382 & 1 & 54.382 & 97.161 & .000 \\
\hline & Within Groups & 8.396 & 15 & .560 & & \\
\hline & Total & 62.778 & 16 & & & \\
\hline \multirow[t]{3}{*}{ Knee angle at $\mathrm{MKF}$} & Between Groups & 478.875 & 1 & 478.875 & 56.466 & .000 \\
\hline & Within Groups & 127.211 & 15 & 8.481 & & \\
\hline & Total & 606.086 & 16 & & & \\
\hline \multirow[t]{3}{*}{ EMG \% at IC } & Between Groups & .856 & 1 & .856 & 11.050 & .005 \\
\hline & Within Groups & 1.161 & 15 & .077 & & \\
\hline & Total & 2.017 & 16 & & & \\
\hline \multirow[t]{3}{*}{ EMG \% at MKF } & Between Groups & 2.930 & 1 & 2.930 & 3.941 & .066 \\
\hline & Within Groups & 11.153 & 15 & .744 & & \\
\hline & Total & 14.083 & 16 & & & \\
\hline
\end{tabular}

\section{Results}

\section{Frontal-Plane Knee Angle}

At IC, women landed in valgus $\left(-0.180 \pm 0.718^{\circ}\right)$, and men landed in varus $\left(3.403 \pm 0.773^{\circ}\right)(\mathrm{P}<.001)$. At MKF, men reached a greater varus position $(15.543 \pm$ $\left.2.419^{\circ}\right)$ than women $\left(4.910 \pm 3.389^{\circ}\right)(\mathrm{P}<.001)$.

\section{Biceps Femoris Activation}

Women's BF aRMS amplitude (1.301 \pm 0.275 at IC, 2.329 \pm 0.526 at MKF) was less than men $(0.852 \pm 0.280$ at IC, $1.497 \pm 1.073$ at MKF). At IC, BF aRMS amplitude significantly differed between groups $(\mathrm{P}<.05)$. However, no significance difference between groups at MKF $(\mathrm{P}>$ $.05)$. 


\section{Discussion}

The purpose of this study was to determine genderrelated differences in knee valgus motion during a drop jump in Physical Education major undergraduate students. Identification of these differences may help elucidate mechanisms of increased incidence of ACL injuries among student athletes. As we known, limiting the valgus position of the knee during a single-leg landing could reduce strain on the ACL and in turn reduce the number of non-contact ACL injuries. Our results suggest that women land in greater knee valgus and less BF activation than men, but BF activation just differs at IC and does not differ at MKF between the sexes.

A single-leg landing involving forceful valgus with the knee close to extension has been identified as a common mechanism of ACL injury (Olsen, Myklebust, Engebretsen and Bahr, 2004; Boden, Dean, Feagin and Garrett, 2000). Our findings demonstrate that during a single-leg landing, women displayed greater valgus knee angles than men. Evidence has been presented by Russell et al (Russell, Palmieri, Zinder and Ingersoll, 2006) when subjects performed a single-leg drop jump in a similar test. Women landed with larger maximal valgus knee angles and exhibited higher peak adduction loads (Hewett, Myer and Ford, 2005) at the knee joint complex than their male counterparts. Because increasing valgus positioning by $5^{\circ}$ from a neutral alignment can increase the load on the ACL by 6 times (Bendijaballah, ShiraziAdl and Zukor, 1997), the finding that women land with greater knee valgus than men may help to uncover one of the underlying factors contributing to the sex disparity in ACL injuries.

Russell et al (2006) have identified that women were in knee valgus whereas men were in knee varus before contacting with the ground. They suggested that women may be preprogrammed with an ineffective and potentially hazardous landing strategy. Totally 32 subjects (16 men and 16 women) were in their test, they found that 2 of their male subjects demonstrated a similar landing strategy to that of their female subjects (landing at IC with a valgus knee angle equal to or above the mean of the females and remaining in more relative valgus at MKF). Interestingly, upon closer examination of our data, we found that 2 of our female subjects demonstrated a varus knee angle during landing but no male subjects landing with a valgus knee angle at IC and MKF.
So we agree that individuals landing in knee valgus before ground contact may represent a preprogrammed strategy that possibly place them at risk for ACL injury. Further examination of this potentially detrimental landing technique may provide clinicians and scientists with a screening tool to identify athletes predisposed to future knee injury.

Since the landing technique dictates how forces are distributed in the knee. Landing with greater knee valgus supports the notion that women may adopt a ligamentdominant strategy, relying on passive structures to resist and absorb ground reaction forces and promoting ligament failure (Ford, Myer and Hewett, 2003). Some injury prevention programs, which focusing on dynamic control of knee motion in the sagittal plane and reduction of frontal-plane movement and torques may help to prevent ACL injury. Such as Sportsmetrics, a plyometric training program, has been shown to effectively reduce varus and valgus torques and, thus, may be effective in diminishing the incidence of ACL injury (Myer, Ford, Palumbo and Hewett, 2005). Actually, further understanding of how much frontal-plane motion in vivo is hazardous and whether valgus knee angle can predict ACL injury would be of value in order to better understand its importance in ultimately causing ACL failure.

We hypothesized that men would display greater BF activation than women, because men have a relatively stronger BF which providing dynamic stability to the knee joint, decreasing knee valgus, and preventing placing strain on the ACL. Our data support this hypothesis, but just at the landing position of IC. At MKF, no difference in BF muscle activation was observed between men and women. As we known BF is one of the hamstrings which co-activates with the quadriceps in order to generate enough posteriorly directed force on the tibia to produce a mechanically significant decrease in the load on the ACL or to assist in stabilizing the knee, or both, thereby maintaining a physiologically safe tension in the ligament or safeguarding the ligament from additional tension, or both. However, our findings question that whether hamstrings and quadriceps activate differ in their rate between IC and MKF, and whether BF plays an equal effort between sexes at MKF. Further research is necessary to understand more muscles' activation in lower limb at their positions of landing. 
As we observed in the tests, BF activation increases with the increase in knee flexion angle during landing. It may be a strategy that helps to transfer forces from the lower extremity up through the trunk (Anderson and Pandy, 2003; Devita and Skelly, 1992; Nadler, Malanga, DePrince, Stitik and Feinberg, 2000) or may have resulted from femoral movement from a more valgus to a varus position. During drop landing, a subject's total energy is transformed from potential to kinetic energy, which includes impact or ground reaction forces (Devita and Skelly, 1992). The landing technique usually involves movements that act to dissipate these forces (Devita and Skelly, 1992). Although our results show that women display less BF activation than men at IC, upon closer examination of our data, 2 of our female subjects demonstrated a varus knee angle during landing and 1 of them displayed BF activation equal to and even above the mean of the males. This female has a relatively longer and stronger BF. Such results suggest that individual differences, such as muscle strength, muscle length and landing technique or strategy do contribute to and may be the factors in knee stabilization mechanism regardless of gender differences.

\section{Limitations}

The methods we employed to establish joint kinematics in the current investigation are commonly used and deemed acceptable, but it is also important to acknowledge their limitations. Although 4 cameras video acquisition systems were used in our tests, the problems of missing points and mismatching positions are still serious. In order to capture the motions accurately, increase the number of cameras and the acquisition frequency of systems are preferred. Besides, a skin-based retroreflective marker system and its associated motion artifact may not definitively predict underlying movement of the bones. Along similar lines, we acknowledge that sagittal-plane motion can influence frontal-plane motion using such techniques. As such, it is possible that if the knee flexion angles at each position were distinctly different between men and women, our measures of frontal-plane motion could represent a difference in kneeflexion angle, rather than a sex difference. However, the overall records of knee-flexion angles were similar between groups. Thus, we are confident that our results do reflect sex or gender differences in frontal-plane knee angles.
The sampling rate at $100 \mathrm{~Hz}$ is quite too low for collecting the BF electromyography data. According to the Nyquist sampling theorem, samples must be taken, based on the bandwidth of the signal. It states that if a bandlimited dc signal is sampled at a rate that is twice the highest frequency component in the signal, the sample values exactly describe the original signal. Since $\mathrm{BF}$ is a large muscle group, if it is possible, sampling rate at $1000 \mathrm{~Hz}$ can describe the original signal more accurately.

We did not assess the skill level of our subjects, which potentially could affect our results. Arendt and Dick (1995) have noted skill level as a factor predisposing women to ACL injury. Although we cannot disregard that skill level may have played a role in the observed sex difference, both study groups were randomly selected in the Physical Education major students regardless what kind of sports they usually involved in.

\section{Conclusions}

During a sing-leg drop landing, women displayed a greater valgus knee angle at IC and remained in more relative valgus at MKF than men. Based on our results, one could conclude that the tendency for women to remain in a greater relative valgus position than men throughout the landing may help to explain the sex disparity in ACL injury. Besides, women performed different and less Biceps Femoris muscle activation than men at IC but no difference at MKF. Further investigation is needed to uncover the stabilization mechanism in landing knee motion between IC and MKF.

\section{Acknowledgement}

The author would like to thank Dr. Smith, Andrew W. and Dr. Wilkinson, John G. for their critical reviews and assistance. Special thanks for the technical support by Ms. Chen, Ruby W.P. at the Human Performance Laboratory of HKIEd. 


\section{References}

Anderson, F.C., \& Pandy, M.G. (2003). Individual muscle contributions to support in normal walking. Gait Posture. 17, 159-169.

Arendt, E. \& Dick, R. (1995). Knee injury patterns among men and women in collegiate basketball and soccer: NCAA data and review of literature. American Journal of Sports Medicine, 23, 694-701.

Arendt, E.A., Agel, J., \& Dick, R. (1999). Anterior cruciate ligament injury patterns among collegiate men and women. Journal of Athletic Training, 34, 86-92.

Bendijaballah, M.Z., Shirazi-Adl, A., \& Zukor, D.J. (1997) Finite element analysis of human knee joint in valgus-varus. Clinical Biomechanics (Bristol, Avon), 12, 139-148.

Boden, B.P., Dean, G.S., Feagin, J.A.Jr., \& Garrett, W.E.Jr. (2000). Mechanisms of anterior cruciate ligament injury. Orthopaedics, 23, 573.

Chaudhari, A.M., \&Andriacchi, T.P. (2006). The mechanical consequences of dynamic frontal plane limb alignment for non-contact ACL injury. Journal of Biomechanics, 39, 330-338.

Devita, P., \& Skelly, W.A. (1992). Effect of landing stiffness on joint kinetics and energetics in the lower extremity. Medicine and Science in Sports and Exercise, 24, 108-115.

Ford, K.R., Myer, G.D., \& Hewett, T.E. (2003). Valgus knee motion during landing in high school female and male basketball players. Medicine and Science in Sports and Exercise, 35, 1745-1750.

Ford, K.R., Myer, G.D., Toms, H.E., \& Hewett, T.E. (2005). Gender differences in the kinematics of unanticipated cutting in young athletes. Medicine and Science in Sports and Exercise, 37, 124-129.
Griffin, L.Y., Agel, J., Albohm, M.J., Arendt, E.A., Dick, R.W., Garrett, W.E., Garrick, J.G., Hewett, T.E., Huston, L., Ireland, M.L., Johnson, R.J., Kibler, B., Lephart, S., Lewis, J.L., Lindenfeld, T.N., Mandelbaum, B.R., Marchak, P., Teitz, C.C., \& Wojtys, E.M. (2000). Noncontact anterior cruciate ligament injuries: risk factors and prevention strategies. Journal of the American Academy of Orthopaedic Surgeons, 8, 141.

Hewett, T.E., Myer, G.D., Ford, K.R., Heidt, R.S., Colosimo, A.J., McLean, S.G., van den Bogert, Paterno, M.V., \& Succop, P. (2005). Biomechanical measures of neuromuscular control and valgus loading of the knee predict anterior cruciate ligament injury risk in female athletes: a prospective study. American Journal of Sports Medicine, 33, 492-501.

Kernozek, T.W., Torry, M.R., Hoof, H.V., Cowley, H., \& Tanner, S. (2005). Gender differences in frontal and sagittal plane biomechanics during drop landings. Medicine and Science in Sports and Exercise, 37, 1003-1012.

Kirkendall, D.T., \& Garrett, W.E.Jr. (2000). The anterior cruciate ligament enigma: injury mechanisms and prevention. Clinical Orthopaedics. 375, 64.

McLean, S.G., Huang, X., Su, A., \& van den Bogert, A.J. (2004). Sagittal plane biomechanics cannot injure the ACL during sidestep cutting. Clinical Biomechanics (Bristol, Avon), 19, 828-838.

McLean, S.G., Lipfert, S.W., \& van den Bogert, A.J. (2004). Effect of gender and defensive opponent on the biomechanics of sidestep cutting. Medicine and Science in Sports and Exercise, 36, 1008-1016.

Myer, G.D., Ford, K.R., Palumbo, J.P., \& Hewett, T.E. (2005). Neuromuscular training improves performance and lower-extremity biomechanics in female athletes. Journal of Strength and Conditioning Research, 19, 51-60.

Nadler, S.F., Malanga, G.A., DePrince, M., Stitik, T.P., \& Feinberg, J.H. (2000). The relationship between lower extremity injury, low back pain, and hip muscle strength in male and female collegiate athletes. Clinical Journal of Sport Medicine, 10, 89-97. 
Olsen, O.E., Myklebust, G., Engebretsen, L. \& Bahr, R. (2004). Injury mechanisms for anterior cruciate ligament injuries in team handball: a systematic video analysis. American Journal of Sports Medicine, 32, 1002-1012.

Russell, K.A., Palmieri, R.M., Zinder, S.M., \& Ingersoll, C.D. (2006). Sex differences in valgus knee angle during a single-leg drop jump. Journal of Athletic Training, 4l(2), 166-171.

Stalbom, M., Holm, D.J., Cronin, J.B., \& Keogh, J.W.L. (2007). Reliability of kinematics and kinetics associated with Horizontal Single leg drop jump assessment. A brief report. Journal of Sports Science and Medicine, 6, 261-264.

\section{Correspondence:}

Sam Ka-lam

Department of Health and Physical Education, The Hong Kong Institute of Education Address: 10 Lo Ping Road, Tai Po, New Territories, Hong Kong

Phone : (852) 29488081

Fax : (852) 29488082

E-mail : samsam@ied.edu.hk 